\title{
B.J. Baars and N.M. Gage (eds): Cognition, brain and consciousness
}

\author{
Elsevier Academic Press: Burlington, MA, USA, Oxford, UK, 2nd Edition, 2010 pp653 \\ (ISBN: 978-0-12-375070-9)
}

\section{Di Rocco}

Received: 7 May 2010 /Accepted: 7 May 2010 / Published online: 29 June 2010

(C) Springer-Verlag 2010

Cognitive neuroscience, the combined study of mind and brain, is probably the most fascinating field of scientific and philosophic exploration. This extremely exciting book provides the reader the necessary basic information to appreciate how the traditional separation between the mind and the brain is nowadays challenged by the nomological network generated by the careful observation of the biological-neurological events and the related cognitiveinferred concepts. Indeed, even though the ancient debate mind versus body has never ceased to be a subject of discussion by scientists and philosophers, currently it has become again a productive and stimulating scientific question, mainly because of the availability of functional neuroimaging techniques that has attracted the convergent interest of biologists, neuroscientists, and psychologists.

The book is organized in 16 chapters: an introductory chapter on Mind and Brain, two chapters concerning the general organization of the brain with particular regard to the neurons and their connections, a chapter specifically devoted to the neuroimaging of the living brain and, finally, a chapter illustrating the basic encephalic anatomy introduces six more focused sections. These sections deal with the vision, the hearing and the speech, the consciousness and the attention, the learning process and the memory, and the thinking and problem solving ability. The last seven chapters concern cognitive and emotional processes. They address the language, how we decide goals and control action, the emotion, and how we perceive the mental states of others, that is, the social cognition. Two final chapters conclude the textbook, focusing on the brain development and the genes and the molecules of cognition, respectively, together with an appendix devoted to the methods for observing the living brain.

The chapter on the genes and the molecules is a new addition to the previous edition of the book. Further additions are a new glossary of technical terms and a new mini-atlas of the brain. Some chapters have been revised completely. The views of scientists around the world are presented in boxes collectively called Frontiers in Cognitive Neurosciences. As a result, this second edition looks quite appealing and the editors should be very proud of it. The numerous elegant and very instructive colored figures and schemas as well as the quality of printing enrich the "charme" of this book, which certainly deserves to be suggested to anyone interested in a better insight on the neurological, emotional, and cognitive processes of our brain. 